Original Research Article

\title{
Isoniazid induced hepatotoxicity and its amelioration with ethanolic extract of stem bark of Berberis lycium Royale in mice
}

\author{
Saima Rafiq*, Khalida Ajmal, Ayesha Afzal
}

Department of Pharmacology,

Wah Medical College, Wah

Cantt, Pakistan

Received: 30 March 2017

Revised: 24 May 2017

Accepted: 27 May 2017

*Correspondence to:

Dr. Saima Rafiq,

Email: saimarafiqu34@

gmail.com

Copyright: () the author(s), publisher and licensee Medip Academy. This is an openaccess article distributed under the terms of the Creative Commons Attribution NonCommercial License, which permits unrestricted noncommercial use, distribution, and reproduction in any medium, provided the original work is properly cited.

\begin{abstract}
Background: To study the hepatoprotective effect of Ethanolic extract of Stem Bark of Berberis lycium Royale in isoniazid (INH) induced hepatotoxicity in mice model.

Methods: The study design was lab based randomized controlled in-vivo study in mice conducted from $9^{\text {th }}$ April 2014 till $9^{\text {th }}$ May 2014 at animal house of National Institute of Health, Islamabad. Group A was on normal diet and water and hepatotoxicity was produced by giving isoniazid $(50 \mathrm{mg} / \mathrm{kg} \mathrm{BW})$ in mice of Group B. Group C and D were given isoniazid (INH) plus low dose and high dose of Ethanolic extract of stem bark of Berberis Lycium Royle respectively.

Results: INH induced hepatotoxicity was depicted by elevated serum LFT's, hepatocytic ballooning, severe steatosis and inflammation. Mice getting concurrent treatment of INH, low and high dose of Ethanolic extract of Berberis Lycium Royle showed decreased serum levels of biomarkers and their liver sections manifested improved histological picture but more significant reduction in toxic effects were observed in animals receiving high dose.

Conclusions: High dose of Ethanolic extract of stem bark of Berberis lycium Royale showed more marked hepatoprotective activity as compare to low doses. The hepatotoxicity of INH can be reduced by concurrent use of INH with ethanolic extracts of Berberis Lycium Royle.
\end{abstract}

Keywords: Berberis lycium Royale, Hepatoprotective, Isoniazid (INH), LFT's, Steatosis

\section{INTRODUCTION}

Isoniazid (INH) is first line anti-tuberculosis drug. ${ }^{1}$ Evidence shows that it produces hepatotoxicity in $12 \%$ of patients as serious adverse effect. ${ }^{2}$ Three mechanisms i.e direct cell stress, specific immune reactions and direct mitochondrial impairment are involved in drug induced hepatotoxicity (DIH). ${ }^{3}$ Acetylhydrazine, a metabolite of INH is the main culprit to induce hepatotoxicity. ${ }^{4}$ INH induced hepatotoxicity is depicted by elevated serum LFT's (AST, ALT, ALP and total Bilirubin). Histological sections of liver tissue showed hepatocytic ballooning, steatosis, and inflammation. ${ }^{5-7}$ Previously various studies have been carried out using extracts of Berberis Lycium Royale for its hepatoprotective effect but it was done in combination with other herbs. No research work has been done in isolation on Berberis lycium Royale. Our study was planned to evaluate the protective effect of Low and High doses of ethanolic extract of stem bark of Berberis lycium Royale by measuring serum LFT's and observing histopathological changes of liver. Several experimental works have proved hepatoprotective effect of Berberis lycium Royle. ${ }^{8}$ Berberis lycium Royle is known by various regional names like sumbloo, Barbery, ziarlargay. ${ }^{9}$ Active constituent of stem bark is Berberine $(4.2 \%) .{ }^{10}$ Berberis lycium Royle has significant hepatoprotective effect. ${ }^{11}$ It also have hypoglycemic potential. ${ }^{12}$ It is being used in treatment of rheumatism, jaundice, and eye infections and is very effective for headache, ear injury, and whooping cough. ${ }^{13}$ 
Our purpose of study was to explore the hepatoprotective effects of Low and High doses of Ethanolic extract of stem bark of Berberis lycium Royle independently on isoniazid (INH) induced hepatotoxicity in mice model.

\section{METHODS}

The lab based randomized controlled in vivo study done in National Institute of Health (NIH) after approval from RARE (Riphah Academy of Research and Education) from April to May 2014. Fifity six healthy male albino Balb/C mice, weighing 28-38g were randomly divided into four groups. Group A: $(n=14)$ control group received normal diet and fresh water orally. Group B: $(n=14)$ was given INH 50mg/kg BW. ${ }^{14}$ Group C: $(\mathrm{n}=14)$ was given INH $50 \mathrm{mg} / \mathrm{kg} \mathrm{BW} .{ }^{14}$ and low dose Ethanolic extract 150 $\mathrm{mg} / \mathrm{Kg} \mathrm{BW}$ while Group D: $(\mathrm{n}=14)$ recieved INH 50mg/kg BW. ${ }^{14}$ and high dose $200 \mathrm{mg} / \mathrm{Kg} \mathrm{BW}$ of ethanolic extract of stem bark of Berberis lycium Royle. Herb and the drugs were given once daily through mouth for 1 month.

Stem bark of Berberis lycium Royle was locally collected, dried and powdered. It was authenticated by a botanists from Peshawar university. Extract preparation was done by using $1 \mathrm{~kg}$ of dried fine powder. It was initially soaked in ethanol at $25^{\circ} \mathrm{C}$ for 72 hours. Muslin cloth was used for coarse filtration. While Fine filtration was carried out through Whatman filter paper no.1. Filtrate was firstly evaporated in open air and further evaporation was done by using rotary evaporator at $40^{\circ} \mathrm{C}$ under reduced pressure. The obtained dark brown extract was semi-solid and sticky in consistency. Transparent air tight glass bottles were used to store Ethanolic extract in refrigerator at temperature of $2-8^{\circ} \mathrm{C}$ for future use. Yield of Ethanolic extract was about $20 \%$ (20g was obtained from $100 \mathrm{~g}) .{ }^{15}$

Blood samples were collected at day 0 for baseline, at day 15 for progress of research and finally at $30^{\text {th }}$ day of experiment for serum LFT's. Each time $2 \mathrm{ml}$ of blood was taken through cardiac puncture, serum separated after centrifugation and stored in serum cups at $-20^{\circ} \mathrm{C}$ till further estimation of LFT's. ${ }^{16}$

AST, ALT and ALP kits were purchased from (Merck pharma) while total bilirubin by (Spectrum Diagnostics). Estimation of serum ALT and AST by IFCC method, ALP by Optimised standard method and total bilirubin by Calorimetric method was done. ${ }^{17,18}$ After taking blood samples mice were dissected to take out liver. Liver tissue was sectioned and processed for histopathological examination. Histological sections were assessed qualitatively and quantitatively. Qualitatively, hepatotoxicity was recognized by change in colour and appearance of liver on naked eye examination while ballooning of hepatocytes, steatosis, and inflammatory infiltrates were observed under 40X objective of microscope. Semiquantitative morphological grading was done by using Kleiner criteria for steatosis and hepatocytic ballooning while modified HAI grading was used for inflammatory changes. Statistical results were achieved by using one way ANOVA test on SPSS 20. P <0.05 was used as statistically significant.

\section{RESULTS}

\section{Effect of Berberis lycium Royale on serum Alanine aminotransferase (ALT) levels}

INH resulted in markedly raised level of serum ALT $(185.1 \pm 65.32)$ in mice of Group B as compared to Group A $(53 \pm 4.99)$, but these levels were reduced in mice of Group C (94.6 \pm 14.34$)$ and more significantly reduced in (H.E) group $(55 \pm 3.89)$ treated with $\mathrm{INH}$ and Berberis lycium Royale (Table 1).

\section{Effect of Berberis lycium Royale on serum Aspartate aminotransferase (AST) levels}

Results depicted that serum AST was significantly increased ( $p<0.001)$ in mice of Group B given INH only as compared to Group A, but these levels were markedly reduced in mice of Group $\mathrm{C}$ and further reduced in Group $\mathrm{D}$ treated with INH and Berberis lycium Royale.

\section{Effect of Berberis lycium Royale on serum Alkaline phosphatase (ALP) levels}

Serum ALP level was greatly increased $(p<0.001)$ in mice of Group B given INH as compared to Group A. ALP levels were found to be reduced in Group $\mathrm{C}$ with more marked reduction in Group D treated with INH and Berberis lycium Royale.

Table 1: Comparison of Liver Function Tests (LFT's) in different groups.

\begin{tabular}{|lllll|}
\hline Animal group no. $(\mathbf{n}=10)$ & T. Bil $(\mathbf{m g} / \mathbf{d l})$ & ALT $(\mathrm{U} / \mathrm{L})$ & AST (U/L) & ALP (U/L) \\
\hline Group A & $(0-0.9 \mathrm{mg} / \mathrm{dl})$ & $(17-77 \mathrm{U} / \mathrm{L})$ & $(54-298 \mathrm{U} / \mathrm{L})$ & $(35-96 \mathrm{U} / \mathrm{L})$ \\
\hline Group B & $0.10 \pm 0.0$ & $53 \pm 4.99$ & $107.1 \pm 18.46$ & $88.6 \pm 1.24$ \\
\hline Group C & $1.30 \pm 0.070$ & $185.1 \pm 65.32$ & $431.9 \pm 57.32$ & $175.6 \pm 30.89$ \\
\hline Group D & $0.76 \pm 0.246$ & $94.6 \pm 14.34$ & $202.3 \pm 35.65$ & $110.3 \pm 13.21$ \\
\hline p-value & $0.16 \pm 0.108$ & $55 \pm 3.89$ & $109.4 \pm 15.06$ & $90.9 \pm 9.18$ \\
\hline
\end{tabular}

$*=\mathrm{p}$ - value Significant

$(\mathrm{ALT}=$ Alanine aminotransferase, $\mathrm{AST}=$ Aspartate aminotransferase,

ALP=Alkaline Phosphatase, T. Bil=Total Bilirubin) 
Table 2: Post-hoc comparison of total bilirubin and ALT between the groups.

\begin{tabular}{|ll|lll|}
\hline Group comparisons & Total Bilirubin & Column1 & ALT & Column2 \\
\hline & Mean difference & p-value & Mean difference & p-value \\
\hline Group A vs. Group B & -1.18 & $<0.001^{*}$ & -131.1 & $<0.001^{*}$ \\
\hline Group A vs. Group C & -0.66 & $<0.001^{*}$ & -41.6 & 0.078 \\
\hline Group A vs. Group D & -0.06 & 0.974 & 3 & 1 \\
\hline Group B vs. Group C & 0.5 & $<0.001^{*}$ & 88.5 & $<0.001^{*}$ \\
\hline Group B vs. Group D & 1.1 & $<0.001^{*}$ & 133.1 & $<0.001^{*}$ \\
\hline Group C vs. Group D & 0.6 & $<0.001^{*}$ & 44.6 & $0.048^{*}$ \\
\hline
\end{tabular}

Table 3: Post-hoc comparison of AST and ALP between the groups.

\begin{tabular}{|lllll|}
\hline & Mean difference & p-value & Mean difference & p-value \\
\hline Group A vs. Group B & -322.8 & $<0.001^{*}$ & -86 & $<0.001^{*}$ \\
\hline Group A vs. Group C & -95.2 & 0.247 & -21.7 & 0.849 \\
\hline Group A vs. Group D & 3.7 & 1 & -0.8 & 1 \\
\hline Group B vs. Group C & 226.6 & $<0.001^{*}$ & 63.3 & $0.015^{*}$ \\
\hline Group B vs. Group D & 355.7 & $<0.001^{*}$ & 84.2 & $<0.001^{*}$ \\
\hline Group C vs. Group D & 129.1 & $0.044^{*}$ & 20.9 & 0.868 \\
\hline
\end{tabular}

$*=$ p- value Significant $(\mathrm{ALT}=$ Alanine aminotransferase, AST= Aspartat aminotransferase, ALP=Alkaline Phosphatase, T. Bil=Total Bilirubin)

\section{Effect of Berberis lycium Royale on serum total bilirubin levels}

Raised serum total bilirubin levels were observed in Group B given INH only as compared to control Group A. But raised bilirubin level was reduced in Group $\mathrm{C}$ followed by significant reduction $(\mathrm{p}<0.001)$ in Group D both treated with INH and Berberis lycium Royale).

\section{Histopathological examination}

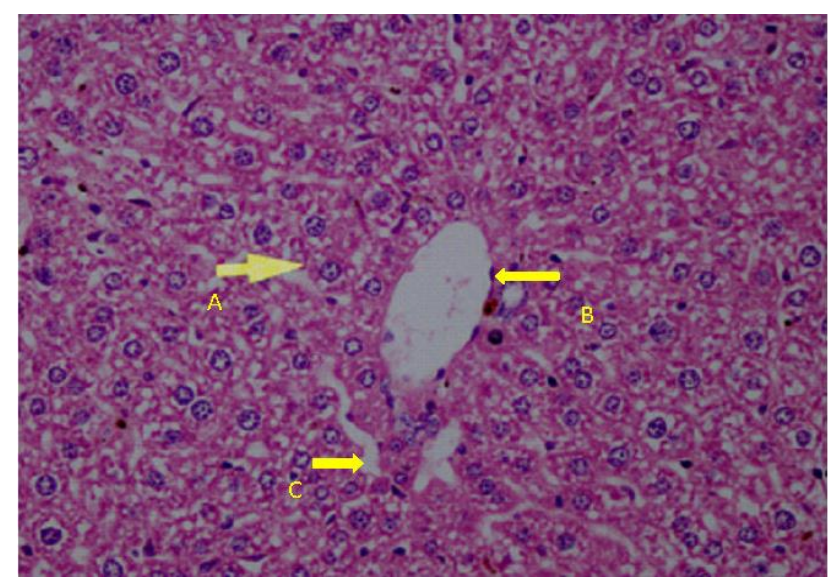

Figure 1: The section of liver of an animal no. 1 of control group $\mathrm{C}$ showing [Hepatocytes (A), Central vein (B), Sinusoid space (C)] $\mathrm{H}$ and $\mathrm{E}$ stain, $40 \mathrm{X}$.

Color of liver was reddish brown with smooth surfaces. $\mathrm{H}$ and E preparations of liver sections of Group A showed normal gross appearance on histological examination i.e. microscopically normal lobular appearance having normal portal tract, central vein, and radiating cords of hepatocytes (Figure 1).

Group B mice given INH only caused severe hepatotoxicity showing severe steatosis, prominent hepatocytic ballooning and severe heavy inflammatory infiltrates (Figure 2).
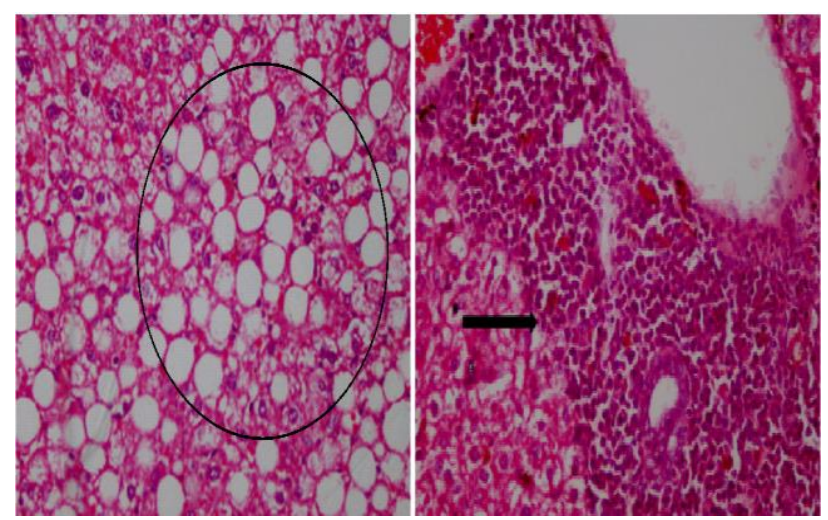

Figure 2: The section of liver specimen of drug treated group showing severe steatosis and portal inflammation (A)- $\mathrm{H}$ and $\mathrm{E}$ stain, 40X.

Histopathological examination of $\mathrm{H}$ and $\mathrm{E}$ preparations of liver sections of ethanolic extract treated group showed reversal of severe inflammation to mild portal, perivenular and intralobular inflammation. Mild steatosis and few ballooned cells were observed in Group C. Minimal hepatocytic ballooning, minimal inflammation and minimal steatosis was observed in Group D (Figure 3). 


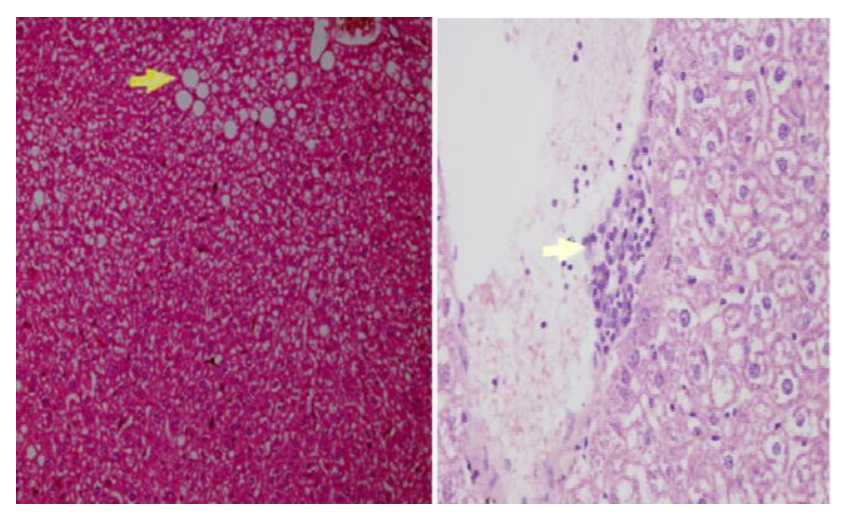

Figure 3: The section of liver specimen of ethanolic extract treated group showing mild steatosis and mild portal inflammation- $\mathrm{H}$ and $\mathrm{E}$ stain, $40 \mathrm{X}$.

\section{DISCUSSION}

The study was conducted to detect INH induced hepatotoxicity by quantitative estimation of serum LFT's and to observe the hepatoprotective potential of ethanolic extract of Berberis lycium Royale in vivo in mice.

INH produced highly deranged serum LFT's (ALT, AST, ALP and total bilirubin) due to hepatotoxicity and liver tissue sections revealed severe steatosis, hepatocytic ballooning and inflammation in Group-B animals with a significant difference in values as compared to Group A animals. Serum T. Bilirubin was increased to $1.30 \pm 0.070$ $\mathrm{mg} / \mathrm{dl} \quad(\mathrm{p}<0.001)$, serum ALT to $185.1 \pm 65.32 \mathrm{mg} / \mathrm{dl}$ $(\mathrm{p}<0.001)$, serum AST to $431.9 \pm 57.32 \mathrm{mg} / \mathrm{dl}(\mathrm{p}<0.001)$ and serum ALP to $175.6 \pm 30.89 \mathrm{mg} / \mathrm{dl}(\mathrm{p}<0.001)$. Similar results were also observed by Hassan in 2012 while inducing hepatotoxicity in rabbit by using isoniazid. ${ }^{5}$ Issabeagloo in 2012 also recorded similar findings by inducing hepatotoxicity in rats with combination of isoniazid and rifampicin. ${ }^{19}$ Hepatotoxicity due to antitubercular drugs is established to be mediated through free radical damage and oxidative stress to hepatocytes. ${ }^{20}$ It is recognized that in sub-acute and chronic inflammation, reactive oxygen species (ROS) play a main role in modulating the inflammatory response and subsequent cell and tissue injury. Antioxidants are documented as probable protective agents in diminishing the oxidative damage of cells from ROS and hamper the progress of many diseases. ${ }^{21}$ Herbal medicine is popular since ancient times due to its comparatively better safety profile. ${ }^{22}$ Medicinal plants have been shown to exert antiinflammatory, anti-stress and anti-cancer effects by modulating the immune function. ${ }^{23,24}$ Among many of the herbs, Berberis lycium Royle, is found to be hepatoprotective. ${ }^{8}$ Berberis lycium is broadly used for the cure of various ailments. Herb consists of major alkaloid berberine. ${ }^{25}$ Berberine boosts up the immune performance of human body. ${ }^{26}$ Our study was designed to explore the hepatoprotective effect of ethanolic extract of Berberis lycium Royle. Our study results showed that ethanolic extract of stem bark of Berberis lycium Royle has significant hepatoprotective activity $(\mathrm{p}<0.001)$ in dose- dependent manner. High dose of extract $(200 \mathrm{mg} / \mathrm{kg}$ body wt.) lowered serum LFT's level to a greater extent as compared to low dose $(150 \mathrm{mg} / \mathrm{kg}$ body wt.). Significant elevation was noticed in levels of serum LFT's in group B which was given INH as compared to group A mice which received no medications. Raised serum LFT's are diagnostic markers of hepatotoxicity. ${ }^{27}$ Combined administration of low and high dose of Berberis lycium Royle ethanolic extract with INH in group C and D restored serum LFT's towards normal level as compared to group B. It was most probably due to anti-oxidant activity of Berberis lycium Royle. Our research results were found in concordance with study done by Ahmed and his fellows in 2008 on crude powder and methanolic extract of Berberis lycium Royle by using paracetamol for induction of hepatotoxicity in rabbits. ${ }^{28}$ Our study results were also found in correlation with work done by Ahmed in 2009 while doing research on Biochemical studies on Berberis lycium Royale and Analysis of its Extracts for Bioactivity showing higher antimicrobial and wound healing activities of methanolic and ethanolic extract of root bark as compare to aqueous extract. ${ }^{29}$ Histopathological studies of liver sections have not been done regarding hepatoprotective role of ethanolic extract of Berberis lycium Royle. Our study showed yellow discoloration and greasy appearance of liver specimens in Group B given INH. Similar observations were recorded by Imber in 2002 while having research on hepatic steatosis and its relationship to liver transplantation. ${ }^{30}$ Steatosis is basic histopathological feature of drug induced liver injury (DILI). Our research showed moderate to severe steatosis in most mice of Group B (Figure 2). Similar histopathological results were also observed by Hassan in 2012 while inducing hepatotoxicity in rabbit by using isoniazid. ${ }^{5}$ Mice given ethanolic extract of Berberis lycium Royle showed reverse of steatotic changes produced by INH giving proof of hepatoprotective potential of ethanolic extracts of Berberis lycium Royle.

Hepatocytic ballooning is also an important marker to distinguish simple steatosis from steatohepatitis. ${ }^{31}$ Our study showed prominent ballooning in most of heptocytes of Group B given INH only which correlate with the research done by Maryam in 2010 who induced hepatotoxicity in rabbits by isoniazid. ${ }^{6}$

Our study results depicted that ethanolic extract of Berberis lycium Royale markedly reversed hepatocytic ballooning with better reversal in high dose ethanolic extract treated group as compare to low dose ethanolic extract treated group.

Group B given only INH showed severe inflammation of hepatocytes. Our results are in accordance with the study done by Hassan in 2012 while inducing hepatotoxicity in rabbit by using isoniazid. ${ }^{5}$ Our research results showed that ethanolic extract of Berberis lycium Royale drastically reverse inflammatory changes $(\mathrm{p}<0.001)$ with more best reversal seen with high dose ethanolic extract group (H.E). Histopathological findings due to INH induced 
hepatotoxicity were improved after giving combination of INH with ethanolic extract of Berberis lycium Royle (Figure 3). Hepatoprotective effect may be due to the flavonoids or polyphenolic compounds, which are ethanol soluble and present in many herbs. Flavonoids and polyphenolic compounds have strong antioxidant activity, which has hepatoprotective role against free radical injury. ${ }^{32}$ No study has been done on ethanolic extract of stem bark of Berberis lycium Royale regarding hepatoprotective activity. Our study results proved the hepatoprotective effects of ethanolic extract of stem bark of Berberis lycium Royale.

\section{CONCLUSION}

This in vivo study provides the evidence of INH induced hepatotoxicity and hepatoprotective activity of ethanolic extract of stem bark of Berberis lycium Royale. INH induced hepatotoxicity can be reduced successfully by concurrent administration of INH and ethanolic extract of stem bark of Berberis lycium Royale.

Funding: No funding sources

Conflict of interest: None declared

Ethical approval: The study was approved by the Institutional Ethics Committee

\section{REFERENCES}

1. Miesel L, Rozwarski DA, Sacchettini JC, Jacobs WR, editors. Mechanisms for isoniazid action and resistance. Genetics and Tuberculosis: Novartis Foundation Symposium, Wiley Online Library; 1998:217.

2. Kumar A. A review on hepatoprotective herbal drugs. IJRPC. 2012;2:92-102.

3. Russmann S, Kullak-Ublick GA, Grattagliano I. Current concepts of mechanisms in drug-induced hepatotoxicity. Current medicinal chemistry. 2009; 16:3041.

4. Metushi I, Cai P, Zhu X, Nakagawa T, Uetrecht J. A Fresh Look at the Mechanism of Isoniazid-Induced Hepatotoxicity. Clinical Pharmacology and Therapeutics. 2011;89:911-4.

5. Hassan AS, Ahmed JH, Al-Haroon SS. A study of the effect of Nigella sativa (Black seeds) in isoniazid (INH)- induced hepatotoxicity in rabbits. Indian journal of pharmacology. 2012;44:678.

6. Maryam S, Aziz K, Bhatti ASA, Shahzad AW. Effects of Jetepar (glucometamine, glucodiamine and nicotinamide ascorbate) on Isoniazid Induced Hepatotoxicity in Rabbits. Annals of King Edward Medical University. 2010;16:37-42.

7. Tayal V, Kalra BS, Agarwal S, Khurana N, Gupta U. Hepatoprotective effect of tocopherol against isoniazid and rifampicin induced hepatotoxicity in albino rabbits. Indian journal of experimental biology. 2007;45:1031

8. Shabbir A, Shahzad M, Arfat Y, Ali L, Aziz RS, Murtaza G, et al. Berberis lycium Royle: A review of its traditional uses, phytochemistry and pharmacology. African Journal of Pharmacy and Pharmacology. 2012;6:2346-53.

9. Murad W, Ahmad A, Gilani SA, Khan MA. Indigenous knowledge and folk use of medicinal plants by the tribal communities of Hazar Nao Forest, Malakand District, North Pakistan. Journal of Medicinal Plants Research. 2011;5:1072-86.

10. Janbaz K, Gilani A. Studies on preventive and curative effects of berberine on chemical-induced hepatotoxicity in rodents. Fitoterapia. 2000;71(1):2533.

11. Girish C, Koner B, Jayanthi S, Rao K, Rajesh B, Pradhan S. Hepatoprotective activity of six polyherbal formulations in paracetamol induced liver toxicity in mice. Indian Journal of Medical Research. 2009;129:569-78.

12. Yin J, Zhang H, Ye J. Traditional Chinese medicine in treatment of metabolic syndrome. Endocrine, metabolic and immune disorders drug targets. 2008;8:99.

13. Ahmed E, Arshad M, Ahmad M, Saeed M, Ishaque M. Ethnopharmacological survey of some medicinally important plants of Galliyat Areas of NWFP, Pakistan. Asian Journal of Plant Sciences. 2004;3:410-5.

14. Pal R, Valphei K, Singh K, Rana S. Garlic confers hepatoprotection in isoniazid rifampicin induced hepatic injury. Ind J Gastro. 2003;1:A100.

15. Mashwani ZUR, Khan MA, Irum S, Ahmad M. Antioxidant potential of root bark of Berberis lycium Royle. From galliyat, western himalaya, pakistan. Pakistan journal of botany. 2013;45:231-4.

16. Akpanabiatu MI UIB, Udosen EO, Udon AE. Rat serum electrolytes, lipid profile and cardiovascular activity on nuclea latifolia leaf extract administration. Indian J Clin Biochem; 2005.

17. Y De. Effects of drugs on clinical laboratorytests: AACC Press Washington; 1995.

18. Tietz NW. Clinical guide to laboratory tests: WB Saunders Co; 1995.

19. Issabeagloo E, Taghizadieh M. Hepatomodulatory Action of Camellia sinensis Aqueous Extract against Isoniazid-Rifampicin Combination Induced Oxidative Stress in Rat. Advances in Bioresearch. 2012;3(3).

20. Sodhi C, Rana S, Attri S, Mehta S, Yaiphei K, Mehta S. Oxidative-Hepatic Injury of Isoniazid-Rifampicin in Young Rats Subjected to Protein and Energy Malnutrition. Drug and chemical toxicology. 1998;21(3):305-17.

21. Agrawal S, Kulkarni G, Sharma V. Antimicrobial and anti-inflammatory activities of bark of four plant species from Indian Origin. 2012.

22. Hoareau L, DaSilva EJ. Medicinal plants: a reemerging health aid. Electronic Journal of Biotechnology. 1999;2(2):3-4.

23. Thatte U, Bhalerao S. Pharmacovigilance of ayurvedic medicines in India. Indian journal of pharmacology. 2008;40(1):S10.

24. Singh N. A comparison of both water and ethanol extracts prepared from Echinacea purpurea and 
Echinacea angustifolia on the response to Influenza A/PR/8/34 infection in mice. 2010.

25. Chand N, Durrani FR, Ahmad S, Khan A. Immunomodulatory and hepatoprotective role of feedadded Berberis lycium in broiler chicks. Journal of the Science of Food and Agriculture. 2011;91(10):173745.

26. Kim TS, Kang BY, Cho D, Kim SH. Induction of interleukin-12 production in mouse macrophages by berberine, a benzodioxoloquinolizine alkaloid, deviates CD4+ T cells from a Th2 to a Th1 response. Immunology. 2003;109(3):407-14.

27. Fernández-Villar A, Sopeña B, Vázquez R, Ulloa F, Fluiters E, Mosteiro M, et al. Isoniazid hepatotoxicity among drug users: the role of hepatitis C. Clinical infectious diseases. 2003;36(3):293-8.

28. Ahmad MA, Chaudhary MZ, Nadeem M, Sharif T, Ahmad B. Hepatoprotective effect of Berberis lycium (Royle) in hepatotoxic rabbits. Gomal Uni J. 2008:24.
29. Ahmed A. Biochemical Studies on Berberis Lyceum Royal and Analysis of its Extracts for Bioactivity: University of Arid Agriculture, Rawalpindi; 2009.

30. Imber CJ, St Peter SD, Handa A, Friend PJ. Hepatic steatosis and its relationship to transplantation. Liver transplantation. 2002;8(5):415-23.

31. Hübscher S. Histological assessment of non-alcoholic fatty liver disease. Histopathology. 2006;49(5):45065.

32. Navarro MC MM, Martin A, Jimenez. J, Utrilla MP. Free radicals and antihepatotoxic activity of Rose measuring tomentosus. Planta Medica; 1992.

Cite this article as: Saima R, Khalida A, Ayesha A. Isoniazid induced hepatotoxicity and its amelioration with ethanolic extract of stem bark of Berberis lycium Royale in mice. Int J Basic Clin Pharmacol 2017;6:1865-70. 